\title{
Pelatihan Good Manufacturing Practice (GMP) pada Usaha Pangan Binaan Universitas Andalas
}

\author{
Tivany Edwin, Reinny Patrisina, Alexie Herryandie Bronto Adi, Prima Fithri, dan \\ Nindy Hidayah \\ Fakultas Teknik, Universitas Andalas, Kampus Limau Manis, Padang, 25163. Indonesia \\ E-mail: tivany@eng.unand.ac.id
}

Keywords:

food industry, GMP, hygiene, production control, training

Kata Kunci: GMP, higienis, industri pangan, pelatihan, pengendalian produksi

\begin{abstract}
Food business is a very promising, but the products must be safe and worth buying. Good manufacturing practices (GMP) are production practices which considering various aspects, such as preventing food contamination during the production process, and production control as well. Small and Medium Enterprises (SME) fostered by Andalas University, which is engaged in the field of food manufacturing, wants to find its products better known and with a wide sales distribution. This can be realized if the business owner has the trust of many consumers. One effort that can be done is to implement the GMP For this reason, SMEs need to receive GMP Training.The method of this event is in the form of training to socialize the concept of GMP for food SMEs fostered by Andalas University, as well as self-assessment of the application of GMP that has been carried out by each SME. The training was held in the presence of 50 SMEs assisted by Andalas University, on Thursday / December 5, 2019 at Amaris Hotel, Padang. Participants were very enthusiastic in attending and actively participating during the training. Self assessment results showed most SMEs have not yet implemented a good GMP in their industry.
\end{abstract}
ABSTRAK
Bisnis pangan merupakan usaha yang menjanjikan, namun produk yang dihasilkan harus aman, layak dikonsumsi serta mempunyai nilai lebih. Good manufacturing practice (GMP) merupakan praktek produksi pangan olahan dengan memperhatikan berbagai aspek, seperti mencegah tercemarnya pangan saat proses produksi, serta pengendalian proses produksi. Usaha Kecil Menengah (UKM) binaan Universitas Andalas yang bergerak di bidang pangan, tentunya ingin produknya lebih dikenal dan dengan distribusi penjualan yang luas. Hal tersebut dapat terwujud jika pemilik usaha telah memiliki kepercayaan dari banyak konsumen. Salah satu upaya yang dapat dilakukan adalah dengan melaksanakan penerapan Good Manufacturing Practice (GMP). Untuk itu UKM tersebut perlu mendapatkan Pelatihan GMP. Metode pelaksanaan pelatihan GMP adalah dengan cara sosialisasi konsep GMP kepada UKM pangan binaan Universitas Andalas, serta self assessment penerapan GMP yang telah dilaksanakan oleh masing-masing UKM. Pelatihan tersebut dihadiri 50 UKM binaan Universitas Andalas, dilaksanakan pada hari Kamis/ 5 Desember 2019 di Hotel Amaris, Padang. Adapun peserta sangat antusias dalam menghadiri dan berperan aktif selama pelatihan berlangsung. Dari hasil self assessment, sebagian besar UKM belum melaksanakan GMP yang baik pada industrinya. 


\section{PENDAHULUAN}

Makanan merupakan kebutuhan dasar manusia, yang akan meningkat seiring bertambahnya populasi masyarakat. Kualitas yang baik dan higienis adalah persyaratan dasar bagi industri makanan. Namun dalam proses produksi makanan, kemungkinan kontaminasi dapat terjadi karena praktik produksi ataupun sanitasi yang kurang baik (Fathonah, 2005). Untuk itu dibutuhkan suatu sistem, agar kualitas keamanan pangan terjaga, salah satunya dengan penerapan Good Manufacturing Practices (GMP) (Kell et al, 1995). GMP merupakan praktik untuk mengendalikan mutu dan higienitas produk melalui pengendalian faktor lingkungan kerja serta proses produksi mencakup disain dan tata letak pabrik, pemeliharaan dan sanitasi, pengendalian proses produksi, sanitasi perorangan, training dan lain-lain. Untuk dapat menghasilkan produk bermutu tinggi dan higienis tidak cukup hanya dengan kegiatan inspeksi, namun mencakup keseluruhan aktifitas pengendalian pada industri terkait.

Pada GMP, terdapat beberapa persyaratan minimum yang harus dipenuhi oleh industri, yakni keamanan pangan, kualitas dan persyaratan hukum. Penerapan yang efektif dari konsep higien dan sanitasi pada sistem GMP, yang akan memberikan keyakinan dan manfaat dalam suatu usaha industri makanan dan industri kemasan terkait (Winarno, 2011).

Ruang lingkup GMP dalam suatu usaha meliputi lokasi, bangunan, fasilitas sanitasi, mesin dan peralatan, bahan, pengawasan proses, produk akhir, uji laboratorium, sanitasi karyawan, pengemasan, label dan keterangan produk, penyimpanan bahan baku dan produk, pemeliharaan dan program sanitasi, pengangkutan produk, dokumentasi dan pencatatan, penarikan produk yang bermasalah dan juga pelaksanaan pedoman yang ada (Menteri Perindustrian Republik Indonesia No. 75/M-IND/PER/7/2010).

Universitas Andalas memiliki beberapa Usaha Kecil Menengah (UKM) yang bergerak di bidang pangan. Permasalahan pada mitra binaan Universitas Andalas, belum sampai sebagian yang memiliki izin usaha seperti PIRT, yang merupakan izin produksi yang dihasilkan industri rumah tangga, dimana izin ini keluarkan oleh Badan pengawasan Obat dan Makanan (BPOM). Hal tersebut berkaitan dengan banyak dari UKM tersebut belum mengenal konsep mengenai praktik manufaktur yang baik. Sedangkan untuk dapat memiliki cakupan pemasaran yang luas dan terpercaya, maka UKM tersebut harus dapat menerapkan praktik manufaktur yang baik, sehingga produk yang dihasilkan memiliki kepercayaan dari masyarakat banyak. Untuk itu tujuan dari kegiatan pengabdian ini adalah agar UKM binaan Universitas Andalas dapat memahami konsep tentang GMP, agar UKM tersebut dapat meningkatkan kelayakan, keamanan dan kualitas produk yang dihasilkan.

\section{METODE}

Adapun pelaksanaan pelatihan ini terdiri dari tahap persiapan dan pelaksanaan. Dalam persiapan juga melibatkan panitia yang merupakan mahasiswa Universitas Andalas. Tim Pemateri dalam pelatihan ini merupakan staf pengajar dari Jurusan Teknik Industri Universitas Andalas, yakni yakni Dr. Reinny Patrisina, Dr. Alexie Herryandie Bronto Adi dan Prima Fithri, MT. Peserta pelatihan merupakan UKM binaan Universitas Andalas yang bergerak di bidang pangan. Tahap persiapan dimulai dari mempersiapkan materi pelatihan bersama dengan tim pengabdian. Kemudian, dilakukan pula diskusi tentang kebutuhan mitra dengan tim pemateri pelatihan. Dalam persiapan tersebut, panitia juga mempersiapkan tempat pelatihan, seminar kit, penyewaan ruangan, daftar absen, dan sertifikat peserta serta panitia, serta mengundang peserta melalui whatsapp group, dan peserta dapat mendaftar melalui link google form yang telah disediakan. 
Untuk tahap pelaksanaan, pelatihan terdiri dari dua sesi, yang pertama adalah materi dari tim pemateri secara presentasi dan tampilan video tentang konsep GMP, dilanjutkan dengan sesi kedua berupa self assessment dari masing-masing UKM tentang pelaksanaan GMP pada usaha masing-masing, yang didampingi oleh tim pemateri. Self assessment berkaitan dengan penerapan GMP pada UKM terkait lokasi, bangunan, fasilitasi sanitasi, peralatan produksi, bahan, produk akhir, labotorium, penyimpanan, pelabelan, karyawan, kemasan, dan pemeliharaan. Poin yang dilihat juga dibuat berdasarkan Peraturan Kepala Badan Pengawas Obat dan Makanan Republik Indonesia Nomor HK.03.1.23.04.12.2206 Tahun 2012 tentang Cara Produksi Pangan Yang Baik Untuk Industri Rumah Tangga. Dengan adanya self assessment ini diharapkan UKM memahami sejauh mana penerapan GMP yang telah dilakukan, dan apa kekurangan yang perlu ditingkatkan agar dapat melaksanakan praktik manufaktur yang lebih baik lagi, sehingga layak untuk mendapatkan sertifikasi.

\section{HASIL DAN PEMBAHASAN}

Pengabdian masyarakat Pelatihan Good Manufacturing Practice (GMP) yang dilaksanakan sebagai bagian dari program Ipteks bagi inkubasi inovasi dunia usaha (IbIIDU) tahun 2019, di bawah binaan LPPM Unand. Acara ini dilaksanakan pada hari Kamis/ 5 Desember 2019 di Hotel Amaris, Padang.

Dari data google form, terdapat 65 peserta yang mendaftar, namun yang mengikuti acara ada 50 UKM bidang pangan yang merupakan binaan Universitas Andalas. Dimana sebagian besar dari UKM ini belum memiliki PIRT, dimana hanya 11 usaha yang telah memiliki PIRT tersebut. Namun ada 6 usaha yang telah memiliki Surat Izin Perdagangan (SIUP). Sebagian besar peserta belum pernah mendapatkan pelatihan GMP sebelumnya.

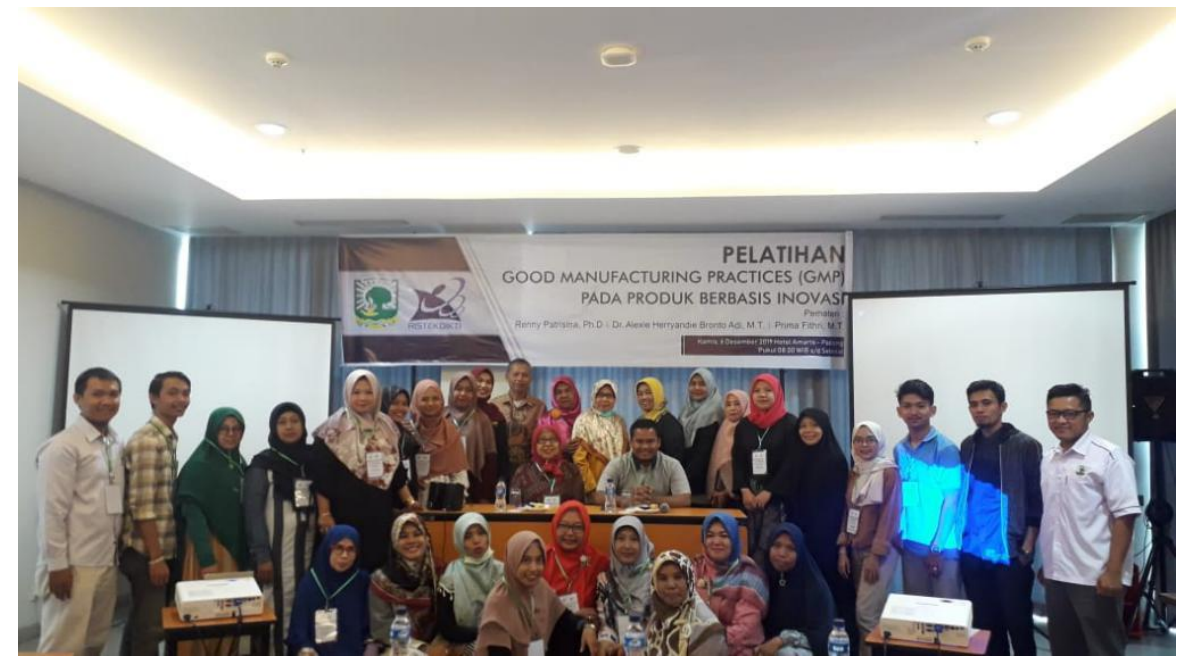

Gambar 1. Foto bersama pemateri dan peserta pelatihan GMP

Sebagian besar UKM yang mengikuti pelatihan berasal dari Kota Padang, dan lainnya berasal daerah lain di sumatera Barat, seperti Pesisir Selatan, Solok, Tanah Datar, dan Dharmasraya. Adapun jenis produk yang diolah UKM terdiri dari produk herbal, kue basah, kukis, roti, gula semut, sirup pala, kopi bubuk, rendang kemasan, yogurt, kefir, keripik, eskrim, permen, makanan catering, saus tomat, nata, virgin coconut oil dan dodol.

Acara pelatihan GMP ini diikuti dengan antusias oleh para peserta dari pukul 08.00 pagi hingga pukul 16.00 sore harinya. Masing-masing peserta diberikan seminar kit berupa goody 
bag, notes, dan ball point. Kemudian peserta diberikan serifikat pelatihan setelah selesai mengikuti acara. Selama pelatihan, para pemateri yang merupakan dosen jurusan teknik industri Universitas Andalas, menampilkan presentasi dan berbagai macam video tentang GMP. Peserta juga diarahkan untuk mengoreksi penerapan GMP yang ditayangkan di video tersebut.

Pelatihan juga terdiri dari self assessment masing-masing UKM terhadap penerapan GMP di masing-masing UKM. Assessment tersebut terdiri dari 12 standar praktik manufaktur yang baik, dan 8 standar monitoring Standard Sanitation Operating Procedure (SSOP). Hasil self assessment tersebut tidak diolah lebih lanjut untuk dipublikasikan. Namun dari hasil self assessment tersebut, UKM dapat melihat bahwa sejauh mana UKM telah menerapkan GMP, serta sejauh mana perlu dilakukan perbaikan agar UKM dapat melaksanakan GMP supaya layak mendapatkan sertifikasi PIRT.
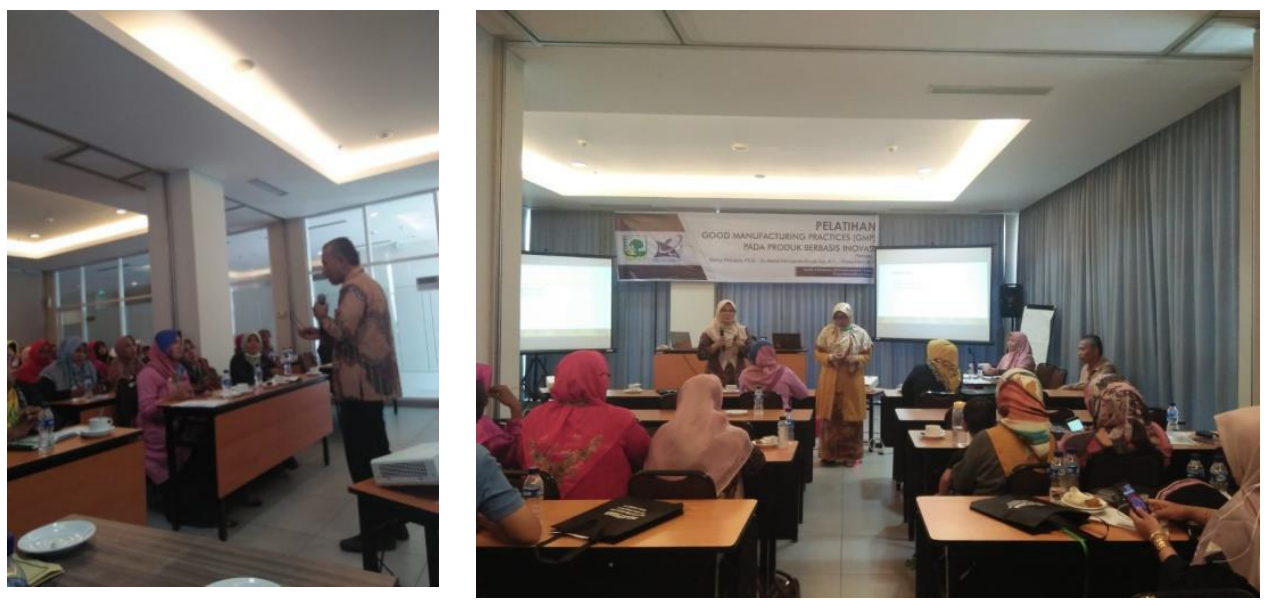

Gambar 2. Pemberian materi oleh narasumber

\section{KESIMPULAN}

Pengabdian masyarakat Pelatihan Good Manufacturing Practice (GMP) pada produk berbasis inovasi dilaksanakan dalam rangka program Ipteks bagi inkubasi inovasi dunia usaha (IbIIDU) tahun 2019, di bawah binaan LPPM Unand. Acara ini dilaksanakan pada hari Kamis/ 5 Desember 2019 di Hotel Amaris, Padang terlaksana dengan baik. Pelatihan GMP dihadiri 50 UKM binaan Unand dan diikuti peserta dengan antusias. Dari self assessment yang dilakukan, peserta UKM dapat mengukur sejauh mana telah melakukan penerapan GMP, begitu juga pada bagian mana dari penerapan GMP yang perlu ditingkatkan. Saran yang dapat diberikan dari hasil evaluasi kegiatan, diharapkan pelatihan GMP ini bekerjasama dengan dinas kesehatan untuk ke depannya, agar kegiatan dapat bersinergi dan menghasilkan manfaat yang lebih optimal untuk peserta UKM yang ikut serta.

\section{UCAPAN TERIMA KASIH}

Adapun Pengabdian Masyarakat ini merupakan program Ipteks bagi inkubasi inovasi dunia usaha (IbIIDU) tahun 2019, dan dibiayai oleh LPPM Unand dengan Nomor Kontrak No. Kontrak T/11/UN.16.17/PM.IbiIIDU/LPPM/2019. Penulis mengucapkan terima kasih kepada pihak LPPM Unand atas kesempatan yang diberikan kepada tim pengabdi. 


\section{DAFTAR PUSTAKA}

Siti Fathonah. 2005. Higiene dan Sanitasi Makanan. Semarang: UNNES Press.

Kell, D. B., \& Sonnleitner, B. (1995). GMP—good modelling practice: an essential component of good manufacturing practice. Trends in Biotechnology, 13(11), 481-492.

Peraturan Kepala Badan Pengawas Obat dan Makanan Republik Indonesia Nomor HK.03.1.23.04.12.2206. 2012. Cara Produksi Pangan Yang Baik Untuk Industri Rumah Tangga.

Menteri Perindustrian Republik Indonesia No. 75/M-IND/PER/7/2010. Pedoman cara produksi pangan olahan yang baik (Good manufacturing Practices).

Wardanu, A.P., dan Anhar, M. 2016. Penerapan Good Manufacturing Practices (GMP) pada Kelompok Usaha Bersama (KUB) WIDA Mantolo Kecamatan Benua Kayong. Jurnal Teknologi Pangan, 7(1): 8-16.

Winarno, F.G. 2011. GMP (Good Manufacturing Practices) Cara Pengolahan Pangan Yang Baik, Bogor: M-Brio Press. 